\title{
Prevalence of significant genetic variants in congenital long QT syndrome is largely underestimated
}

\author{
Elena V. Zaklyazminskaya ${ }^{1 *}$ and Hugues Abriel ${ }^{2}$ \\ ' Laboratory of Medical Genetics, Petrovsky Russian Research Center of Surgery, Moscow, Russia \\ 2 Department of Clinical Research, University of Bern, Bern, Switzerland \\ ${ }^{*}$ Correspondence: zhelene@mail.ru
}

\section{INTRODUCTION}

Congenital long QT syndrome (LQTS) is clinically characterized by the occurrence of syncope due to polymorphic ventricular tachycardia (torsades de pointes), associated to delayed cardiac repolarization that is reflected by a prolongation of the QT interval on the ECG (Webster and Berul, 2008). Thus far, 13 genes coding for ion channel subunits and ion channel regulatory proteins have been found mutated in patients and families with LQTS (Schwartz et al., 2009). The estimated prevalence of LQTS in the general population is reported to be in the range of 1:7000-1:2000 (0.01$0.05 \%)$, without any significant ethnical disparity (Roden and Spooner, 1999; Tester et al., 2006; Schwartz et al., 2009). Different research groups from many countries have reported similar data or cited the same sources (Roden and Spooner, 1999; Tester et al., 2006; Schwartz et al., 2009). Recently, two original studies reported a high prevalence of LQTS founder mutations in the Finnish and Norwegian population (Berge et al., 2008; Marjamaa et al., 2009). In Finland, it was concluded that 1 out of 250 individuals $(0.4 \%)$ carry a LQTS founder mutation (Marjamaa et al., 2009). In Norway, the prevalence of LQTS mutation carriers was estimated to be close to $1 \%$, which is a prevalence that is the highest documented worldwide (Berge et al., 2008). These findings are of clear interest to researchers and clinicians since they may not be only relevant for the Finnish and Norwegian populations, but may also give some important clues about the actual worldwide distribution of genetic variants predisposing to cardiac arrhythmias. In a study looking at variants in KCNQ1 in a subgroup with the longest QTc interval (403-443 ms) from French general population of 100 non-related and non-treated individuals from the DESIR cohort, two new mutations in KCNQ1 were found (Gouas et al., 2004). This study suggests that such low-penetrant variants might be found with $2 \%$ frequency within one "healthy" cohort after screening of one only one gene of interest. As it can be seen, there are clear discrepancies in estimations of LQTS mutation prevalence depending on the sources.

Long QT syndrome is considered as a Mendelian arrhythmic disorder which is transmitted mainly in an autosomal dominant mode of inheritance (Priori et al., 2008). Thus, one should be able to apply the basic concepts of genetics such as Mendel's law for families and Hardy-Weinberg equation for population in equilibrium. Hereafter, we analyze and interpret published data and our own results to estimate the prevalence of LQTS using different approaches.

\section{HYPOTHESIS 1: CONGENITAL LOTS IS A RARE DISEASE}

We postulate that there is no obvious reason to consider that the populations in which the distribution of LQTS mutations has been studied are not in genetic equilibrium. Thus, we can use the HardyWeinberg equation stating that, in such a population, the sum of mutated and normal alleles frequencies is 1 (i.e., $p+q=1$, where " $p$ " - frequency of normal allele, " $q$ " - cumulated frequencies of mutant alleles; Vogel and Motulsky, 1986). It follows that $(p+q)^{2}=1$, provided $0 \leq p \leq 1$; and $0 \leq q \leq 1 ;$ and $p^{2}+2 p q+q^{2}=1$. For a dominant disease with a sizable probability of survival of compound heterozygous subjects, the number of healthy individuals is $p^{2}$, and the maximum number of mutation carriers (or affected individuals) is $\left(2 p q+q^{2}\right)$.

For our calculations, we assume the prevalence of diagnosed LQTS using averaged published data from population without clear founder effect as 1:4000 $\left(2.5 \times 10^{-4}\right)$. The penetrance of LQTS was reported to range between 0.25 (Priori et al., 1999) and 0.7 (Goldenberg et al., 2008), but could be higher, i.e., 0.88, for specific mutations (Brink et al., 2005). Considering an average penetrance of 0.5 , the prevalence of carriage of at least 1 mutant allele should amount to about $5 \times 10^{-4}$. For rare dominant diseases, $p$ tends to 1 , and in this case, $2 p q \rightarrow 2 q$, and $\left(2 p q+q^{2}\right) \rightarrow 2 q$. It can therefore be stated that $2 q+q^{2}=5 \times 10^{-4}$; and simple arithmetic calculations gives us $2 q=5 \times 10^{-4}$, and $q^{2}=6.25 \times 10^{-8}$. In such a case, the frequency of double-mutation carriers in LQTS cohorts can be calculated as $\left(q^{2} / 2 q+q^{2}\right)=\left(q / 2+q^{2}\right)$ and would equal $1.25 \times 10^{-4}$, or $0.0125 \%$ within the group of interest. This calculation looks trivial and consistent, but here one is facing with a strong discrepancy between such an expected frequency of double-mutation carriers and data obtained from large studies (Westenskow et al., 2004; Fodstad et al., 2006; Daubert et al., 2007). As a matter of fact, the prevalence of compound heterozygous has been reported to amount from 4 to $7.9 \%$ in several cohorts of LQTS patients (Splawski et al., 2000; Westenskow et al., 2004; Itoh et al., 2010), and the carrying of three independent mutations was found in about $1 \%$ of genotype-positive patients (Kapplinger et al., 2009). These observations are in accordance with our own findings. Since 1998, we have analyzed 120 index patients with inherited arrhythmic syndromes of Russian origin and have found about $7 \%$ of double-heterozygous probands among the LQTS families. Incomplete clinical diagnostics of LQTS or inaccuracies of our calculations cannot explain satisfactorily this $\sim 300$ - to 600 -fold difference between expected and observed rates. This discrepancy could mean, however, that the actual prevalence of LQTS varies among population and is largely underestimated.

\section{HYPOTHESIS 2: THERE IS NO RELIABLE DATA ABOUT LOTS PREVALENCE}

It is possible to estimate the prevalence of disease-causing mutations assuming that the observed number of compound heterozygous in LQTS cohorts is correct. Indeed, 
patients with more than one mutation in LQTS genes usually show a more severe clinical phenotype (Bezzina et al., 2003; Miller et al., 2004; Westenskow et al., 2004; Fodstad et al., 2006; Richter and Brugada, 2006; Daubert et al., 2007), and it is difficult to misdiagnose them. Ex hypothesis, the population is in equilibrium (HardyWeinberg ratio holds true) but the frequency of LQTS is unknown. If we assume that the mutation events in different alleles are independent, the prevalence of carriers with an additional mutation (double event) within a LQTS population should be similar to the prevalence of one-mutation carriers (single event). The prevalence of double-mutation carriers among LQTS patients is on average 0.07 (see above). This result suggests that about $7 \%$ of individuals in population worldwide may carry genetic alterations in LQTS genes with potential clinical significance. Here, the conclusion would be the same - the prevalence of LQTS genotype is currently strongly underestimated. We do not find any strong argument against this conclusion, but it may seem to be too much to be true. However, a very recent report (Refsgaard et al., 2012) provides strong support to this concept. Analyzing the data of the NHLBI GO Exome Sequencing Project looking at missense and nonsense genetic variants in a North European control cohort, it was estimated that prevalence of unique LQTS-associated variants in 5298 individual studied is 1:31, and the prevalence of LQTS variants found in at least three alleles is about 1:37 (Refsgaard et al., 2012). In total, this corresponds to $6 \%$ of the alleles of this control cohort, not including large insertion/deletion and intronic splice variants.

We have no clear way how to solve the discrepancies resulting from these calculations. These observations suggest conclusions and raise questions that need to be solved.

1. The numbers, which we accept as being the prevalence of LQTS, represents the disease "detectability"; whereas the frequency of cardiac channelopathies, in particular LQTS, is underestimated. This prevalence may run up to several percents, not only in specific ethnic groups, but also worldwide.

2. There are gene variants, found in patients with inherited arrhythmic syndromes, changing biophysical proper- ties of ion channels such as p.V1951L and p.P2006L in SCN5A gene, p.T8A in KCNE2, and p.D85N in KCNE1, but which are considered as polymorphisms because of their frequencies in control groups close to $1 \%$ (Sesti et al., 2000; Nishio et al., 2009; Shinlapawittayatorn et al., 2011). The list of such variants could be continued. It seems to us, that one should be very careful to consider such variants as having no consequence taking into account the probability of high prevalence of LQTS alleles and low disease penetrance. Furthermore, their impact could vary in the presence of ion channel gene mutations in the second allele or in reaction to a given drug, which may lead to drug-induced LQTS.

3. Cost of DNA diagnostics is decreasing rapidly from year to year allowing large scale screening technologies of carriers of non-malignant genetic variants, with so-called form fruste of LQTS, who are unaware of their status. Indeed, there are many factors including a long list of drugs and clinical situations that can trigger life-threatening episodes in such patients.

The accurate estimation of LQTS prevalence is not only of academic interest. Current researches in human genetics tend to increase the amount of genes to analyze, and the size of control group (usually, healthy or untested individuals) to test the rarity of given variant. At that rate, a variant found in a control group of several hundred volunteers can be easily classified (or re-classified) as non-pathogenic. It is clear that next generation sequencing techniques are providing us a more comprehensive data and new insights about genetic bases of monogenic disorders. One has to say that, at this stage, the analyses and interpretation of such data are still very complex.

Finally, here three unanswered questions that we would like to raise:

1. What would be an optimal combination of methods and criteria to use for an accurate and predictive characterization of gene variants in patients with channelopathies?

2. What would be the best DNA diagnostics strategy for patients with suspected LQTS, and how we can deal with functional variant/mutation carriers?
3. Should congenital LQTS, and inherited arrhythmias in general, still be considered as monogenic disorders?

We are convinced that realistic solutions to these questions will provide an invaluable assistance to cardiologic practice and genetic counseling.

\section{ACKNOWLEDGMENTS}

We are grateful to Professor Jacques Beckmann (UNIL, Lausanne) for the interesting discussion and useful comments. The groups of Elena V. Zaklyazminskaya and Hugues Abriel are supported by a grant for scientific co-operation between Eastern Europe and Switzerland by the Swiss National Science Foundation (\#IZ73Z0_128016).

\section{REFERENCES}

Berge, K. E., Haugaa, K. H., Früh, A., Anfinsen, O. G., Gjesdal, K., Siem, G., Oyen, N., Greve, G., Carlsson, A., Rognum, T. O., Hallerud, M., Kongsgård, E., Amlie, J. P., and Leren, T. P. (2008). Molecular genetic analysis of long QT syndrome in Norway indicating a high prevalence of heterozygous mutation carriers'. Scand. J. Clin. Lab. Invest. 68:5, 362-368.

Bezzina, C. R., Rook, M. B., Groenewegen, W. A., Herfst, L. J., van der Wal, A. C., Lam, J., Jongsma, H. J., Wilde, A. A., and Mannens, M. M. (2003). Compound heterozygosity for mutations (W156X and R225W) in SCN5A associated with severe cardiac conduction disturbances and degenerative changes in the conduction system. Circ. Res. 92, 159-168.

Brink, P.A., Crotti, L., Corfield, V., Goosen, A., Durrheim, G., Hedley, P., Heradien, M., Geldenhuys, G., Vanoli, E., Bacchini, S., Spazzolini, C., Lundquist, A. L., Roden, D. M., George, A. L. Jr., and Schwartz, P. J. (2005). Phenotypic variability and unusual clinical severity of congenital long-QT syndrome in a founder population. Circulation 112, 2602-2610.

Daubert, J. P., Zareba, W., Rosero, S. Z., Budzikowski, A., Robinson, J.L., and Moss, A. J. (2007). Role of implantable cardioverter defibrillator therapy in patients with long QT syndrome. Am. Heart J. 153(Suppl.), 53-58.

Fodstad, H., Bendahhou, S., Rougier, J. S., LaitinenForsblom, P. J., Barhanin, J., Abriel, H., Schild, L. Kontula, K., and Swan, H. (2006). Molecular characterization of two founder mutations causing long QT syndrome and identification of compound heterozygous patients. Ann. Med. 38, 294-304.

Goldenberg, I., Zareba, W., and Moss, A. J. (2008). Long QT syndrome. Curr. Probl. Cardiol. 33, 629-694.

Gouas, L., Bellocq, C., Berthet, M., Potet, F., Demolombe, S., Forhan, A., Lescasse, R., Simon, F., Balkau, B., Denjoy, I., Hainque, B., Baró, I., and Guicheney, P. (2004). New KCNQ1 mutations leading to haploinsufficiency in a general population. Defective trafficking of a KvLQT1 mutant. Cardiovasc. Res. 63, 60-68.

Itoh, H., Shimizu, W., Hayashi, K., Yamagata, K., Sakaguchi, T., Ohno, S., Makiyama, T., Akao, M., Ai, T., Noda, T., Miyazaki, A., Miyamoto, Y., Yamagishi, M., Kamakura, S., and Horie, M. (2010). Long QT syndrome with compound mutations is associated 
with a more severe phenotype: a Japanese multicenter study. Heart Rhythm 7, 1411-1418.

Kapplinger, J. D., Tester, D. J., Salisbury, B. A., Carr, J. L., Harris-Kerr, C., Pollevick, G. D., Wilde, K. K., and Ackerman, M. J. (2009). Spectrum and prevalence of mutations from the first 2,500 consecutive unrelated patients referred for the FAMILION long QT syndrome genetic test. Heart Rhythm 6, 1297-1303.

Marjamaa, A., Salomaa, V., Newton-Cheh, C., Porthan, K., Reunanen, A., Karanko, H., Jula, A., Lahermo, P., Väänänen, H., Toivonen, L., Swan, H., Viitasalo, M., Nieminen, M. S., Peltonen, L., Oikarinen, L., Palotie, A., and Kontula, K. (2009). High prevalence of long QT syndrome founder mutations in the Finnish population. Ann. Med. 10, 12.

Miller, T. E., Estrella, E., Myerburg, R. J., Garcia de Viera, J., Moreno, N., Rusconi, P., Ahearn, M. E., Baumbach, L., Kurlansky, P., Wolff, G., and Bishopric, N. H. (2004). Recurrent third-trimester fetal loss and maternal mosaicism for long-QT syndrome. Circulation 109,3029-3034.

Nishio, Y., Makiyama, T., Itoh, H., Sakaguchi, T., Ohno, S., Gong, Y. S., Yamamoto, S., Ozawa, T., Ding, W. G., Toyoda, F., Kawamura, M., Akao, M., Matsuura, H., Kimura, T., Kita, T., and Horie, M. (2009). D85N, a KCNE1 polymorphism, is a disease-causing gene variant in long QT syndrome. J. Am. Coll. Cardiol. 54, 812-819.

Priori, S., Napolitano, C., and Schwartz, P. (1999). Low penetrance in the long-QT syndrome: clinical impact. Circulation 99, 529-533.

Priori, S., Napolitano, C., and Schwartz, P. (2008). "Genetics of cardiac arrhythmias," in Braunwald's Heart Disease, 8th Edn, eds P. Libby, R. O. Bonow,
D. L. Mann, and D. P. Zipes (Philadelphia: Saunders Elsevier), 101-110.

Refsgaard, L., Holst, A., Sadijadieh, G., Haunsø, S., Nielsen, J., and Olesen, M. (2012). High prevalence of genetic variants previously associated with LQT syndrome in new exome data. Eur. J. Hum. Genet. PMID: 22378279. [Epub ahead of print].

Richter, S., and Brugada, P. (2006). Risk-stratifying Jervell and Lange-Nielsen syndrome from clinical data. J. Cardiovasc. Electrophysiol. 17, 1169-1171.

Roden, D. M., and Spooner, P. M. (1999). Inherited long QT syndromes: a paradigm for understanding arrhythmogenesis. J. Cardiovasc. Electrophysiol. 10, 1664-1683.

Schwartz, P. J., Stramba-Badiale, M., Crotti, L., Pedrazzini, M., Besana, A., Bosi, G., Gabbarini, F., Goulene, K., Insolia, R., Mannarino, S., Mosca, F., Nespoli, L., Rimini, A., Rosati, E., Salice, P., and Spazzolini, C. (2009). Prevalence of the congenital long-QT syndrome. Circulation 120, 1761-1767.

Sesti, F., Abbott, G. W., Wei, J., Murray, K. T., Saksena, S., Schwartz,P.J., Priori, S. G., Roden, D.M., George, A.L.Jr., and Goldstein, S.A. (2000).A common polymorphism associated with antibiotic-induced cardiac arrhythmia. Proc. Natl. Acad. Sci. U.S.A. 97, 10613-10618.

Shinlapawittayatorn, K., Du, X. X., Liu, H., Ficker, E., Kaufman, E. S., and Deschênes, I. (2011). A common SCN5A polymorphism modulates the biophysical defects of SCN5A mutations. Heart Rhythm 8, 455-462.

Splawski, I., Shen, J., Timothy, K. W., Lehmann, M. H., Priori, S., Robinson, J. L., Moss, A. J., Schwartz, P. J., Towbin, J. A., Vincent, G. M., and Keating, M. T. (2000). Spectrum of mutations in long-QT syn- drome genes. KVLQT1, HERG, SCN5A, KCNE1, and KCNE2. Circulation 102, 1178-1185.

Tester, D. J., Cronk, L. B, Carr, J. L., Schulz, V., Salisbury, B. A., Judson, R. S., and Ackerman, M. J. (2006). Allelic dropout in long QT syndrome genetic testing: a possible mechanism underlying false-negative results. Heart Rhythm 3, 815-821.

Vogel, F., and Motulsky, A. G. (1986). Human Genetics. Problems and Approaches, 2nd Edn, Vol. 1. Berlin: Springer-Verlag.

Webster, G., and Berul, C. I. (2008). Congenital longQT syndromes: a clinical and genetic update from infancy through adulthood. Trends Cardiovasc. Med. 18, 216-224.

Westenskow, P., Splawski, I., Timothy, K., Keating, M. T., and Sanguinetti, M. C. (2004). Compound mutations a common cause of severe long-QT syndrome. Circulation 109, 1834-1841.

Received: 24 January 2012; accepted: 06 April 2012; published online: 27 April 2012.

Citation: Zaklyazminskaya EV and Abriel H (2012) Prevalence of significant genetic variants in congenital long QT syndrome is largely underestimated. Front. Pharmacol. 3:72. doi: 10.3389/fphar.2012.00072

This article was submitted to Frontiers in Pharmacology of Ion Channels and Channelopathies, a specialty of Frontiers in Pharmacology.

Copyright (c) 2012 Zaklyazminskaya and Abriel. This is an open-access article distributed under the terms of the Creative Commons Attribution Non Commercial License, which permits non-commercial use, distribution, and reproduction in other forums, provided the original authors and source are credited. 